Research, part of a Special Feature on Navigating Trade-offs: Working for Conservation and Development Outcomes

\title{
The Role of Participatory Modeling in Landscape Approaches to Reconcile Conservation and Development
}

\author{
$\underline{\text { Marieke Sandker }}^{1}$, Bruce M. Campbell $^{2,3}$, Manuel Ruiz-Pérez $^{1}, \underline{\text { Jeffrey A. Sayer }}^{4,5}$, Richard Cowling $^{6}$, \\ Habtemariam Kassa ${ }^{7}$, and Andrew T. Knight ${ }^{6,8}$
}

\begin{abstract}
Conservation organizations are increasingly turning to landscape approaches to achieve a balance between conservation and development goals. We use six case studies in Africa and Asia to explore the role of participatory modeling with stakeholders as one of the steps towards implementing a landscape approach. The modeling was enthusiastically embraced by some stakeholders and led to impact in some cases. Different stakeholders valued the modeling exercise differently. Noteworthy was the difference between those stakeholders connected to the policy process and scientists; the presence of the former in the modeling activities is key to achieving policy impacts, and the latter were most critical of participatory modeling. Valued aspects of the modeling included stimulating cross-sector strategic thinking, and helping participants to confront the real drivers of change and to recognize trade-offs. The modeling was generally considered to be successful in building shared understanding of issues. This understanding was gained mainly in the discussions held in the process of building the model rather than in the model outputs. The model itself reflects but a few of the main elements of the usually rich discussions that preceded its finalization. Problems emerged when models became too complex. Key lessons for participatory modeling are the need for good facilitation in order to maintain a balance between "models as stories" and technical modeling, and the importance of inviting the appropriate stakeholders to achieve impact.
\end{abstract}

Key Words: conservation and development; landscape approach; multiple stakeholders; natural resource policy; participatory modeling; systems modeling

\section{INTRODUCTION}

Integrated conservation and development projects emerged in the $1970 \mathrm{~s}$ and represent major investments by conservation organizations. However, their effectiveness is seriously questioned (McShane and Wells 2003, Garnett et al. 2007). A new wave of investment is now emerging in "landscape approaches" as a way to integrate conservation and development (Sayer and Campbell 2004, Sayer and Maginnis 2005).

Landscapes are considered as mosaics of land cover types that provide environmental services and development opportunities for the multiple needs of diverse stakeholders. A landscape approach seeks to understand landscape dynamics and the desired changes from different viewpoints, the aim being to identify interventions and policies that will achieve the stated goals of stakeholders. Constituting a forum for stakeholder negotiations is a fundamental first step in taking a landscape approach (Sayer and Maginnis 2005).

"Facilitated", "mediated", "group", or "participatory" modeling are terms used for building models with non-modelers under the guidance of a skilled modeler. Participatory modeling has been used in a wide range of situations, including business (Vennix 1996, Vennix et al. 1996), fisheries (Otto and Struben 2004), and environmental decisionmaking (e.g., Van den Belt et al. 1998, Vanclay et

\footnotetext{
${ }^{1}$ Autonomous University of Madrid, Spain, ${ }^{2}$ Center for International Forestry Research, Bogor, Indonesia, ${ }^{3}$ Challenge Program for Climate Change, Agriculture and Food Security, University of Copenhagen, Denmark, ${ }_{4}$ International Union for Conservation of Nature, Gland, Switzerland, ${ }^{5}$ Faculty of Earth and Environmental Sciences, James Cook University, Cairns, Queensland, Australia, ${ }^{6}$ Botany Department, Nelson Mandela Metropolitan University, Port Elizabeth, South Africa, ${ }^{7}$ Center for International Forestry Research, Addis Ababa, Ethiopia, ${ }^{8}$ current affiliation: Department of Conservation Ecology and Entomology, Stellenbosch University, Matieland, South Africa
} 
al. 2006). A wide range of model types have been used in participatory modeling, including Bayesian or belief networks (Lynam et al. 2002), agent based modeling (Bousquet and Le Page 2004, Castella et al. 2005) and system dynamics modeling (Van den Belt 2004, Sandker et al. 2007).

Although models are widely used to predict and plan, participatory models serve to explore options and enrich debate. Rouwette et al. (2002) and Lynam et al. (2007)reviewed different cases where participatory modeling was used, and concluded that it improves communication between stakeholders and this increases understanding of complex systems. Akkermans and Vennix (1997) found that five out of six case studies used participatory modeling successfully to create insights and build consensus. This is confirmed by Bousquet et al. (2007) and Castella et al. (2007), who claim that building models with multistakeholder groups who have different perceptions and objectives helps build a shared understanding of problems. García-Barrios et al. (2008) report that modeling is particularly effective in stimulating cross-sector strategic thinking, and in helping participants confront the real drivers of change and recognize non-linearities and trade-offs. The modeling process helps participants step back and look beyond their own world view to the holistic landscape picture. All of these characteristics help in the implementation of a landscape approach.

In this paper, we examine several case studies where participatory system dynamics modeling was applied to environmental management challenges, and explore how it contributed to promoting a landscape approach. The case studies are drawn from landscapes where conservation and development goals were mutually sought. More specifically, we examine whether participatory modeling helped in conceptualizing the landscape and its dynamics, in exploring possible interventions, and in facilitating discussions among multiple stakeholders. We also present lessons for using participatory modeling.

\section{METHODS}

\section{Background to the case studies}

The case study sites all have extraordinary biodiversity values. The Tri National de la Sangha, which stretches between Cameroon, the Central
African Republic, and the Republic of Congo (hereafter TNS), and Malinau (Indonesia) have vast areas of largely undisturbed rainforest. The TNS houses significant populations of forest elephant (Loxodonta cyclotis), lowland gorilla (Gorilla gorilla gorilla), and chimpanzee (Pan troglodytes troglodytes). Malinau's tropical rainforests are among the world's internationally recognized biodiversity "hotspots" (Mittermeier et al. 2004). Wasa Amenfi West (Ghana), where rainforest is surrounded by agroforests, is also a biodiversity hotspot. The Chilimo Forest (Ethiopia) is a National Forest Priority Area and represents one of the few remnants of dry Afro-montane forests that used to cover the central plateau of Ethiopia. Namaqualand (South Africa) forms part of the Succulent Karoo biodiversity hotspot, which is one of only two arid regions in the world to qualify as such. The Subtropical Thicket Biome (South Africa) forms part of the Maputaland-Pondoland-Albany biodiversity hotspot (Steenkamp et al. 2004) and displays high levels of plant endemism, along with populations of African elephant (Loxodonta africana) and endangered rhinoceros (Diceros bicornis michaeli and Diceros bicornis bicornis).

Some of these landscapes have been subject to recent rapid transformation. In Malinau, many small-scale logging permits were issued as a result of decentralization. In Chilimo, deforestation increased significantly when state control weakened after 1991. These landscapes were selected for this paper because of their high biodiversity values and high levels of poverty, and because all had projects with conservation and development goals. Despite this commonality, the landscapes are highly diverse in their social-ecological contexts and stakeholder makeup. In some of the models, participants included governance as part of the system, notably in the TNS model where governance drastically affected outcomes landscape wide. In other landscapes, the governance component in the model was restricted to implications of specific policies. The characteristics of the landscapes, and the modeling approaches applied in each are described in Table 1.

\section{Model building approach and objective}

In all landscapes, alternative scenarios were simulated to explore the trade-offs between conservation and development (see Table 1). Our approach to participatory modeling builds upon the 
Table 1. Landscape characteristics and details of the modeling approach for each of the six case studies.

\begin{tabular}{|c|c|c|c|c|c|c|c|c|}
\hline \multicolumn{5}{|c|}{ Landscape characteristics } & \multicolumn{4}{|c|}{ Modeling approach } \\
\hline $\begin{array}{l}\text { Total } \\
\text { area } \\
\left(\mathrm{km}^{2}\right)\end{array}$ & $\begin{array}{c}\text { Forest } \\
\text { cover } \\
(\%)\end{array}$ & $\begin{array}{c}\text { Pop- } \\
\text { ulation } \\
\text { pres- } \\
\text { sure } \\
\text { (pers- } \\
\text { on/ } \\
\mathrm{km}^{2} \text { ) }\end{array}$ & $\begin{array}{c}\text { Cash } \\
\text { income } \\
\text { per } \\
\text { capita } \\
\text { (US\$/ } \\
\text { annum) }\end{array}$ & $\begin{array}{l}\text { Land use } \\
\text { pressures }\end{array}$ & Objective & $\begin{array}{l}\text { Steps in process to } \\
\text { produce models }\end{array}$ & $\begin{array}{l}\text { Stakeholder } \\
\text { engagement }\end{array}$ & $\begin{array}{l}\text { No. of } \\
\text { variables } \\
\text { in the } \\
\text { model }\end{array}$ \\
\hline
\end{tabular}

Malinau, Indonesia

$\begin{array}{lllll}42,000>90 & 2 & 180 & \begin{array}{l}\text { Logging and } \\ \text { development of } \\ \text { biofuel plantations }\end{array} & \begin{array}{l}\text { Explore impact on livelihoods and } \\ \text { biodiversity of proposed conversion of } \\ \text { forest to oil palm plantations (Sandker et } \\ \text { al. 2007) }\end{array}\end{array}$

Workshop (2001), District officials, many small researchers, workshops, training representatives of course on modeling, community continuing until 2007 organizations

\section{Wasa Amenfi, Ghana}

\section{$3,465 \quad \sim 25 \quad 55 \quad 600 \quad$ Deforestation for cocoa plantations}

Explore whether carbon payments can halt the conversion of primary and secondary forest into cocoa plantations (Sandker et al. 2010)
Workshop (2008)

District officials, local and international conservation agency staff (International Union for Conservation of Nature - IUCN) logging company representative, landholder an researchers

Five annual workshops, policy briefings, continuing until 2009

Conservation agency from conservation initiatives but came to focus on governance and corruption impacts (Sandker et al. 2009) staff (IUCN, World Wildlife Fund, Wildlife Conservation Society), regional conservation bodies, researchers (20-25 persons per workshop)

20 staff from a forestry college, graduate students, staff of nongovernmental organizations (NGOs), local officials, policy advisors

Work with $\mathrm{PhD}$ student to define model (2003)

None for the modeling part of the project
(2005), policy workshops

\footnotetext{
$\begin{array}{ll}3,686 & \text { Not } \\ \text { natu- }\end{array}$

rally

fully

cove-

red

with

forest

Urban development
irrigated farming, over-grazing, alien plant invasion

Explore different mechanisms to schedule conservation actions
} 


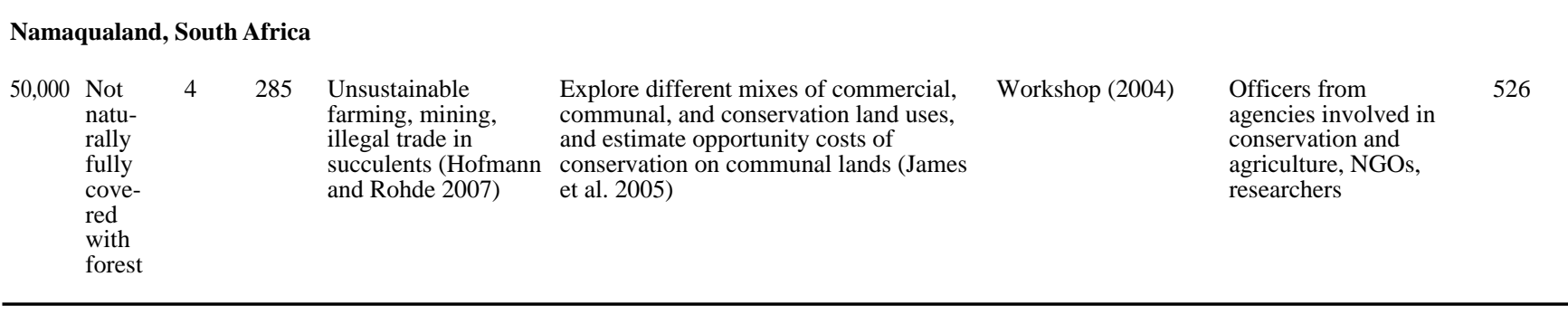

concept of the "throw-away" model: computerimplemented models that are built in a short time to explore a particular problem and are then "discarded" (Sayer and Campbell 2004). This approach is similar to that proposed for scoping models (Van den Belt et al. 1998, Van den Belt 2004, Sandker et al. 2008). The objective of these models is to explore links between the major components of landscape systems and simulate possible trends in environmental and livelihood outcomes over time. The term "throw-away model" stresses the utility of the model in facilitating brainstorming and discussions rather than its use as a formal predictive tool. The process of building the model in a participatory manner is therefore more important than the model produced. King and Kraemer (1993) doubt the usefulness of models with high predictive value in policy making processes. Decisions made that involve multi-stakeholder processes usually go deeper into the social realm where predictions are far from accurate.

In our approach, we collaboratively identify and build scenarios, where the modeled scenarios "tell the story" of envisaged future changes across a landscape. The intention of scenario building is to consider a variety of possible futures rather than to focus on the accurate prediction of a single best outcome (Bennett et al. 2003, Peterson et al. 2003). Ultimately, the objective of the model building exercise is to improve the performance of local stakeholders in identifying interventions that are likely to have the greatest impact on them. In some cases, the objective is also to inform more distant stakeholders at the national, regional, and international levels.

\section{Stakeholders}

These case studies typically aim to help stakeholders find solutions to their conservation and development challenges. Local stakeholders are primarily local landowners, and managers in government and in local and international nongovernmental organizations (NGOs). As part of the process in the TNS, several sessions were held with stakeholders at a policy level (donors, parliamentarians, regional agencies). Policy level dialogue was also part of the Chilimo and Malinau processes.

\section{Model building steps}

The approaches adopted in the six case studies were similar. In all cases, we used the systems dynamic modeling software STELLA. This is a stock-andflow modeling language with a user-friendly iconbased interface. Most commonly, a workshop was held with a diverse range of stakeholders (Table 1), at which a number of activities were facilitated to promote discussion of desirable conservation and development outcomes at the landscape scale (Fig. 1). We often started with historical time trends as a precursor to visioning so as to create awareness of current trends in the landscape and to provoke discussion about the events that triggered changes in the landscape in the past and which might do so in the future. The visioning exercises took several forms: brainstorming on possible future scenarios, identifying "undesired" and "desired" scenarios from different stakeholders' perspectives, identifying the major drivers of change, and discussing possible interventions.

The next step was to identify indicators of conservation and development, which generally became variables in the landscape model, later to be plotted on graphs to display the simulated outcomes under different scenarios. Examples included "household income", "village development budget", "elephant population", and "forest cover". This was typically accomplished by using flip charts and flash cards.

The next step was to define the different sectors (sub-models) of the landscape, for example "rural population dynamics", "land-use changes", and 
Fig. 1. Schematic representation of steps taken in the participatory modeling process (modified from Sandker et al. 2009).

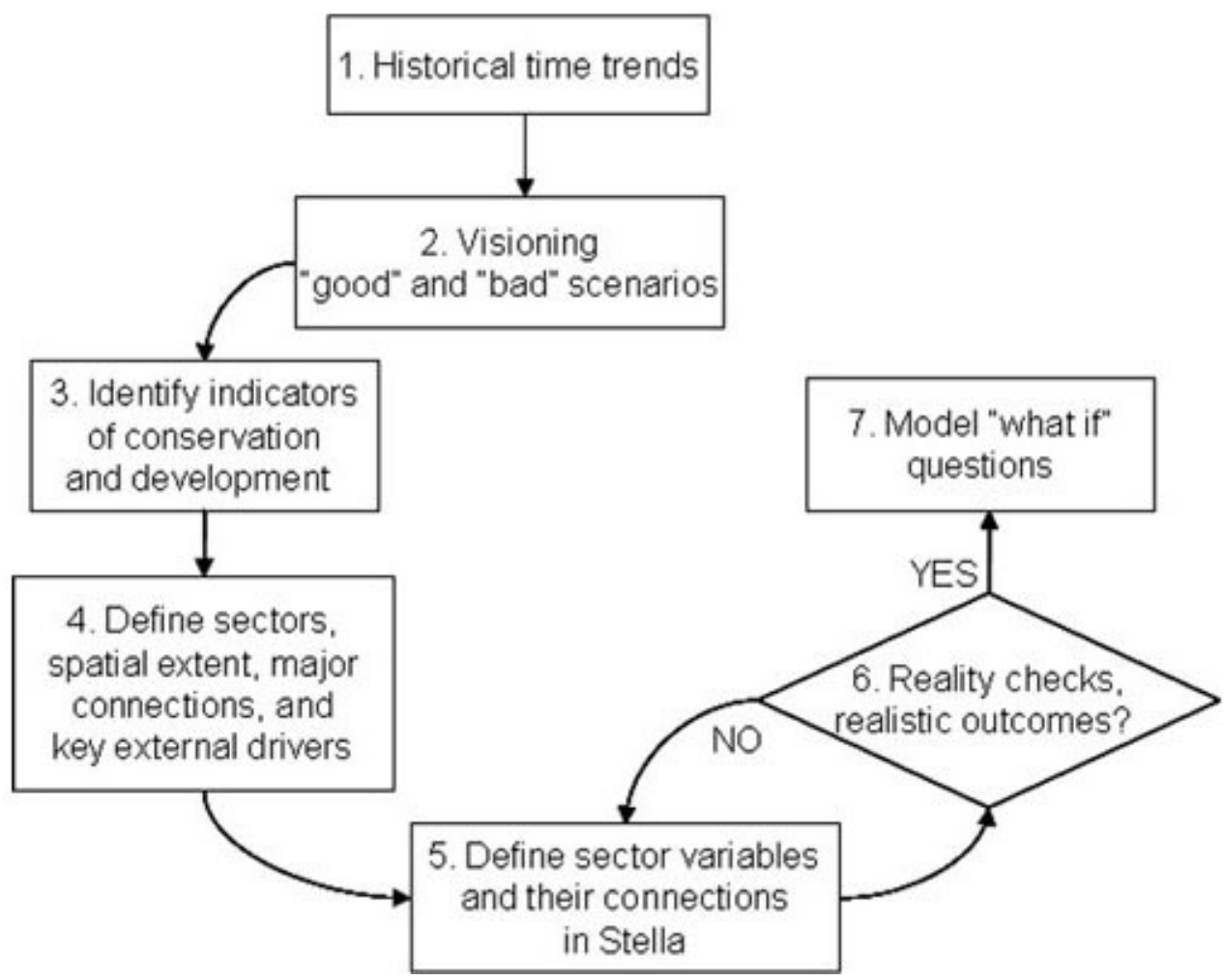

"wildlife populations". Different groups of participants then worked independently to build these sectors under the guidance of specialist modelers. Landscape stakeholders selected the sectors and their elements, including all that they believed were affecting conservation and development outcomes in the landscape. Variables in the sectors were defined and parameterized using data from reports, literature, or expert estimates. The dynamics of the system were added by indicating how variables influence each other, based on the earlier discussions about the main drivers of change. A reality check was typically conducted where the model was run and simulated outcomes for specific variables were checked against known trends or participant expectations, which often led to further changes to the model.

Sectors were then linked to run the complete model. The modeling process often resulted in changes in focus as understanding of the system emerged. This often led to new sectors being added to the model while others became obsolete. The modeling group then explored the potential impacts of different interventions. This allowed participants to ask "what if" questions and served as a reality check for what may be achieved with different interventions.

\section{Time investment}

In some case studies, long-term engagement was possible. This was the case for the TNS (four annual meetings) and Malinau (seven years of engagement with district stakeholders) where the model was revised and updated at each successive meeting. At the other extreme, in the Subtropical Thicket Biome case study, the model was prepared by researchers with the intention of using it in multi-stakeholder forums, but the plan was terminated and the model was not further developed. In Wasa Amenfi, Chilimo, and Namaqualand, models were built at a single workshop. Wasa Amenfi was the shortest workshop, and the model was built in only five days but engagement through email discussions continued for several months. At Chilimo, a 10-day training program was held for lecturers and 
researchers, which included engagement with other local stakeholders. In Namaqualand, a 7-day workshop was held, and the model was refined over the next 12 months.

\section{Evaluation of the participatory modeling case studies}

The value of the participatory modeling cases was assessed through a questionnaire survey of the participants. Twenty-three participants from the six case studies participated in the questionnaire. The participants were grouped into four types of stakeholders: scientists, local/national NGO staff, international NGO staff, and persons closely connected to the policy process. The questions were based on reported qualities from participatory modeling experiences (Akkermans and Vennix 1997, Costanza and Ruth 1998, Rouwette et al. 2002, Van den Belt 2004, Beall 2007). The questions were grouped into four categories that described participatory modeling: (1) "process": the participatory process of building the model and the thinking and discussion it provoked; (2) "structure": the actual model and the more technical aspects of the model building; (3) "outputs": the simulated indicator outputs featured in graphs or tables; and (4) "impact": the impact of the modeling exercise and how the modeling results were used after the model session. The questionnaire had six questions on process, six on structure, six on outputs, and five on impacts (Appendix 1). The questions were structured as Likert statements (Babbie 1989) that were scored from one to five, with one representing a very low perceived value while five represented a high perceived value. The average scores for each case are presented in Appendix 1. The matrix of landscapes and their average scores for the four model building characteristics, and the matrix of stakeholders and their average scores were analyzed using Principal Component Analysis (PCA).

\section{RESULTS AND DISCUSSION}

\section{Modeling characteristics}

Average scores from the participants for the different characteristics of participatory modeling are shown in Figure 2. The highest scores were given to process, whereas impact scored the lowest. The latter characteristic also has the highest standard deviation, indicating a great variety of views about the potential impact of the modeling exercises.
These results are in line with the expectations of the throw-away model approach, where the functioning and outputs of the model are less relevant than the process of discussion, interpretation, and consensus building.

\section{Modeling results in the different landscapes}

The PCA results of the average landscape scores for the four different modeling characteristics (process, structure, outputs, and impact) are shown in Figure 3. The PCA divides the landscapes into three groups: (1) Subtropical Thicket Biome and Namaqualand, (2) Malinau, Chilimo and Wasa Amenfi, and (3) TNS. The X-axis is largely a gradient from low (left) to high (right) scores. The Subtropical Thicket Biome and Namaqualand modeling exercises scored poorly, though in Namaqualand, the modeling process added some value. Malinau, Wasa Amenfi, and Chilimo are landscapes where the modeling was rated highly for all modeling characteristics. The TNS scored high on process, structure, and outputs, but scored poorly on impact. It is noteworthy that the highest scoring case studies concerned models with the fewest number of variables (Fig. 3, Table 1). The Y-axis differentiates between high and low impact. This seems to indicate that process, structure, and outputs are closely related but that other factors influence whether impact is achieved.

The initial model developed by experts for the Subtropical Thicket Biome was highly complex. This raised several problems. The time taken to build the model (about two person-months) was too much in relation to the need to act quickly in the project context. Also, the data needs were too great and the model would have been difficult to explain to the landowners who were the principle stakeholders. In the end, the model was abandoned. The model in this case had become too expertdriven. In Namaqualand, the model was also excessively complex - a simple model would have sufficed. The participatory modeling proved a distraction from the real objective of simply supplying local stakeholders with better information that could have been obtained through other methods.

In the TNS, the modeling gained high scores on process, structure, and outputs, but there was no impact. The explanation of the performance of the 
Fig. 2. Average scores for the four characteristics of the model building exercise derived from the questionnaire survey.

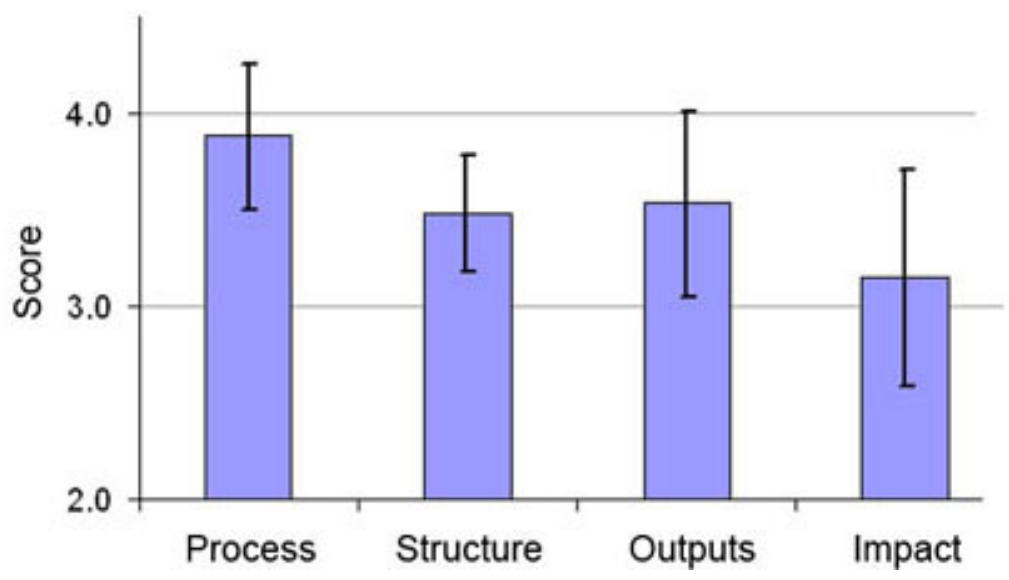

TNS model lies partly beyond the questionnaire results. The model outputs suggested governance was the main problem in the landscape, and little impact was possible without reducing corruption within local government. This considerable challenge lay beyond the mandate of the stakeholders present at the modeling workshop (mainly conservation NGOs) or would put their relationships with government at risk.

In the Malinau, Wasa Amenfi, and Chilimo landscapes, participatory modeling resulted in or came close to having positive impacts. A primary reason why these cases had positive impacts was due to the presence of participants who had strong links to policy makers. This was most obvious in Chilimo where discussions and policy meetings after the modeling exercise resulted in a change in national legislation. For Chilimo, one of the participants was already engaged in policy dialogue with national level actors as the government was revisiting its forest proclamation. The results of the modeling exercise were systematically used to inform the policy formulation process, which led to the inclusion of a law that was relevant to joint management of protected forests (Kassa et al. 2009). In Malinau, the model results were presented and discussed with the district head; the discussions around the model were partially responsible for turning his attention to carbon payment schemes. The experience in Wasa Amenfi served as a lesson on the feasibility of reducing emissions from deforestation and forest degradation (REDD) in comparable landscapes on a global level (Sandker et al. 2010), and the results could contribute to national level negotiations on REDD.

\section{Modeling results for different stakeholders}

The PCA results of the average scores for the different types of participants for the four different modeling characteristics are provided in Figure 4. Each stakeholder type was placed in a distinct group. Again, the $\mathrm{X}$-axis is explained mainly by the overall scores provided by the stakeholders. Scientists are clearly differentiated from the rest; they gave the lowest overall scores (3.3). At the other extreme, stakeholders with connections to the policy process gave the highest overall scores (3.8), and were especially positive in relation to impact. National NGO staff were especially positive about model structure. International NGO staff, located in the middle, gave high scores to most of the characteristics.

\section{THE LIMITATIONS OF PARTICIPATORY MODELING}

\section{Complexity of models}

STELLA is a simple, icon-based modeling language, and therefore is relatively accessible to non-professionals. Most participants confirmed this 
Fig. 3. PCA of average scores for each of the four characteristics of participatory modeling for each landscape.

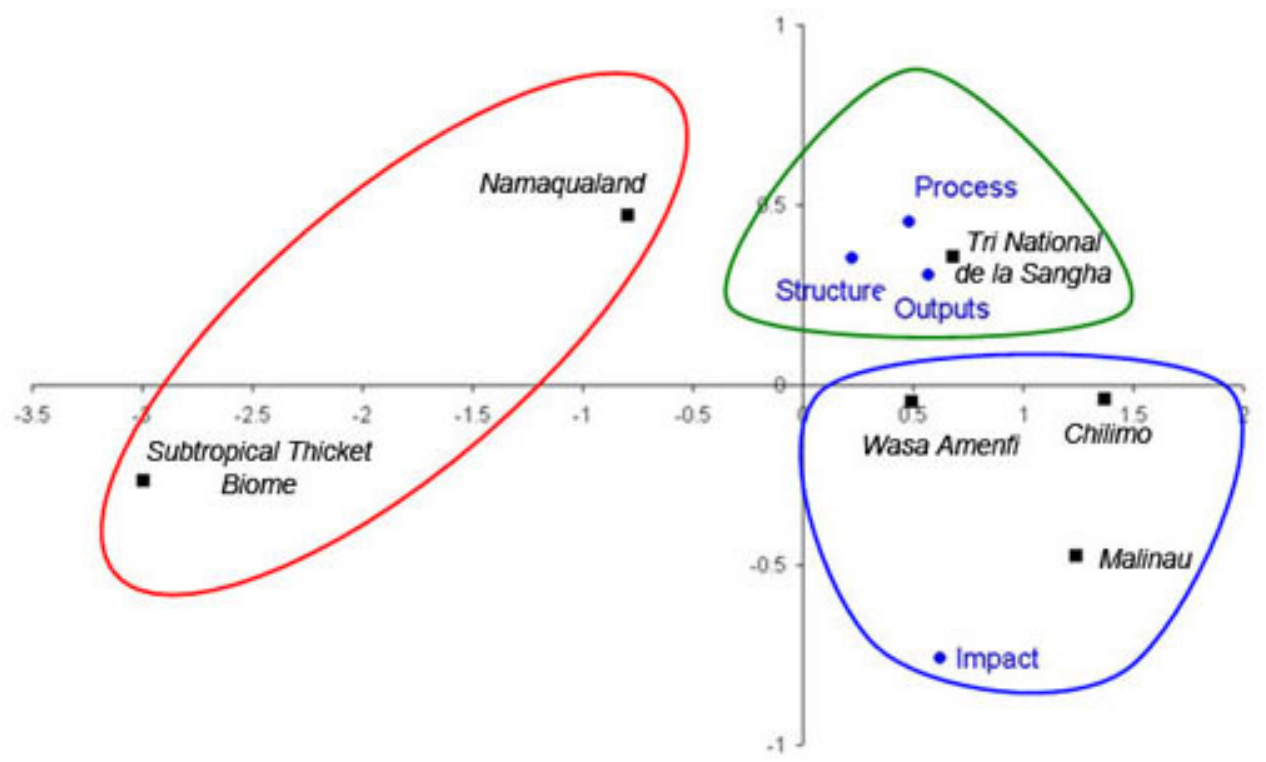

by ranking the user-friendliness of STELLA with a medium to high score (Appendix 1: 2.1). One participant commented "participative workshops are the best strength of STELLA since it is conceptually easy to learn compared to other modeling languages". However, the lowest of all values was given to "the ease to run or alter the model" (Appendix 1: 2.2). Even though it is a relatively simple modeling language, non-modelers experience technical constraints in mastering STELLA. If all the elements of a landscape are included, the model can become highly complex and is no longer easily understood by all stakeholders. Complexity is inherent in the use of system dynamics modeling and forms the biggest limitation to the modeling being a participatory process. We therefore believe the success of participatory modeling depends on the presence of a skilled facilitator. Without good facilitation, the model likely passes into the realm of a high-tech simulation tool and loses its value as a means to stimulate participation and exchange among participants.

\section{Modeling that is "narrow" in scope}

The model structure and outputs gained lower scores than the model building process (Fig. 2). One participant in the Ghana modeling session commented "a multi-dimensional discussion turned into a model with a one-track mind". While the discussion provoked by the model building process was broad, only a small number of options were selected for simulation.

\section{Difficulty to achieve impact}

Changing the way in which people think is a slow and difficult process. In a study by Pala and Vennix (2005) that evaluated whether students' understanding of basic system concepts improved after they took a system dynamics course, the authors suggested that "...it is possible that our students only enrich (i.e., add information to existing conceptual structures) their ideas rather than revising (i.e., changing their beliefs or presuppositions) them." This seems to hold for most of our participants. They gave medium to high scores for "enhancing out-of-discipline thinking" and "focusing on most relevant problems" (Appendix 1: 1.5 and 1.6), but gave lower scores for their ability to apply model outcomes to their daily activities (Appendix 1: 4.2 and 4.3). 
Fig. 4. PCA of average scores for each stakeholder group for the four characteristics of participatory modeling.

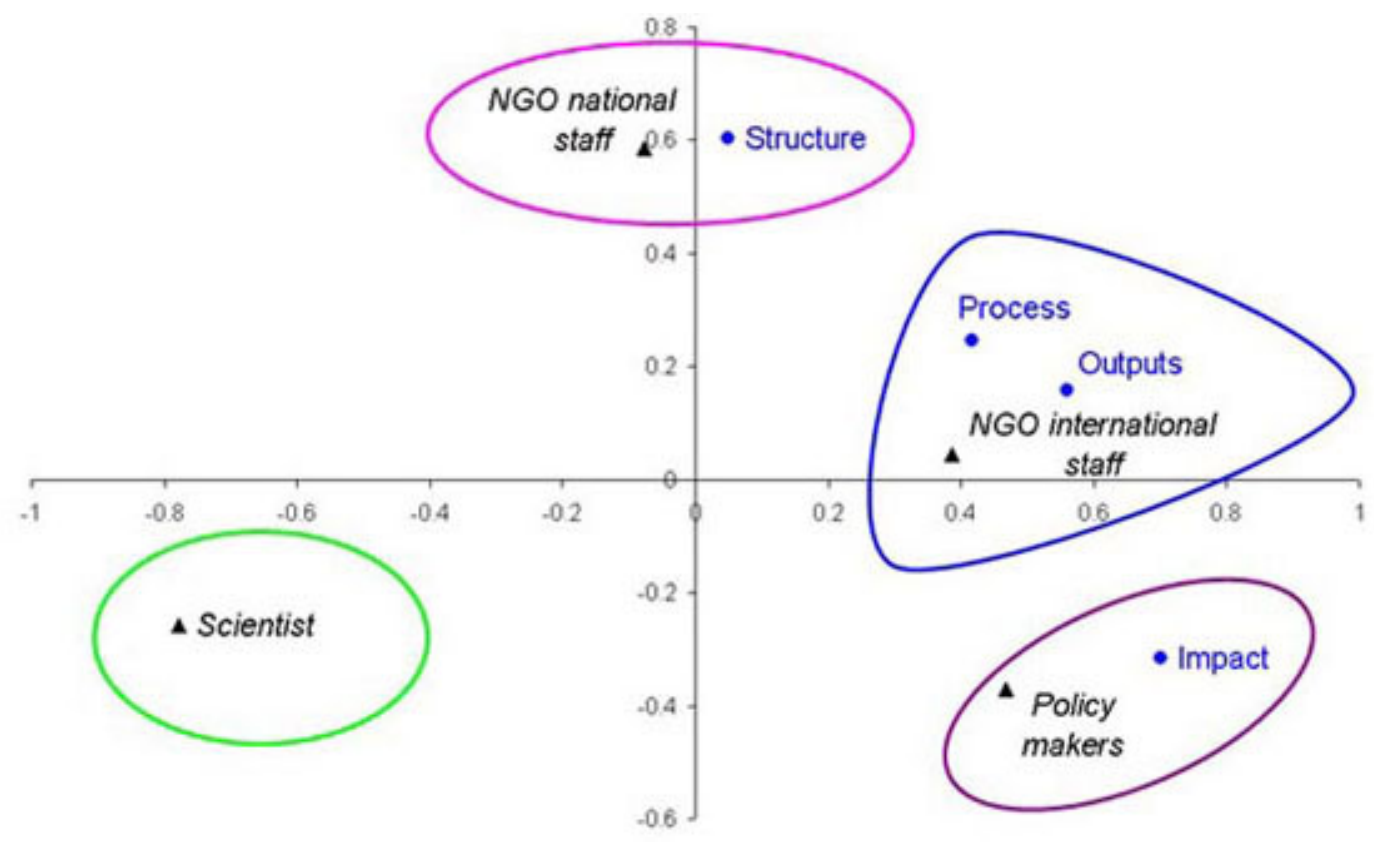

\section{THE STRENGTHS OF PARTICIPATORY MODELING}

\section{Better understanding}

Early stages of model development often revealed a lack of shared understanding of problems among stakeholders. With the exception of the Namaqualand and Subtropical Thicket Biome case studies, high scores were given to the modeling exercise's value in increasing understanding of the landscape (Appendix 1: 1.1) and problems at hand (Appendix 1:1.2). One participant commented that the modeling exercise was " an interesting approach that helps to connect the dots". Several participants also praised the model's capacity to help identify what data should be collected to increase the understanding of the landscape: "It made clear where data is still lacking, which I find a crucial element of planning new activities."

\section{Increasing dialogue}

One of the key needs of a landscape approach is to facilitate multi-stakeholder discussion and negotiation. The participants gave the modeling process moderate to high scores in building consensus on how to proceed (Appendix 1: 1.3) and creating awareness of different viewpoints (Appendix 1: 1.4). One participant mentioned she thought the enriching discussion was not a product of the model but rather of the facilitator's guidance, indicating good facilitation is key if the modeling process is to produce insightful exchange.

Some participants noted that awareness of different viewpoints was restricted because not all stakeholders were included in the modeling exercise. We found it difficult to adequately involve a sufficiently wide cross-section of local landowners and managers because time demands on stakeholders involved in the modeling process often proved excessive. Participation generally extended only as far as officers of NGOs and government agencies.

\section{Enhancing out-of-discipline thinking}

Most participants concluded that they were stimulated to think outside their own discipline (Appendix 1: 1.5). In a number of the case studies, the participants were largely conservationists with a biophysical background. They had a clear view and knowledge of conservation dynamics and how 
they affected these, but their view of development appeared superficial and incomplete (where the gaps were filled by development NGO participants). Despite the development rhetoric of many of the conservation organizations, the models often showed that conservation programs had little positive impact on local livelihoods. The models challenged them to better address the issues influencing the livelihoods of local people.

\section{Confronting the drivers of change}

Most participants believed that participatory modeling was helpful in ensuring focus on the most relevant problems (Appendix 1: 1.6). When building quantitative models, assumptions must be made explicit because they have to be spelled out in scenarios, supported with data, and embodied in the equations used to build the model. The model outputs sometimes resulted in confronting findings - e.g., in the TNS, NGOs realized that the impacts of their current activities on local livelihoods would be negligible unless corruption was confronted (Sandker et al. 2009). This formed the basis for lively debate and a realization that shifts in strategies for investing conservation funds were needed. In Chilimo, where joint forest management is considered to be successful, participants identified future constraints to the system and issues that need to be addressed to sustain the interventions. Malinau comprises a region of extreme change - here, the focus of discussions was on the new challenges and opportunities that are likely to unfold from major external investments.

\section{Formulation of strategy and policy}

Initially, it was believed by those leading the participatory modeling process that the models would be most useful for the participants within their landscapes. The models did contribute to understanding, did help in the exchange viewpoints, and did stimulate out-of-discipline thinking (Appendix 1: 1.1, 1.4, 1.5). However, mean impact scores were low. The best cases of success were outside the landscape. Outputs from the models, usually extremely simplified, can be used to communicate with external stakeholders, including people not involved in the modeling process. This is illustrated by the previously mentioned use of model outputs for the TNS, Chilimo, and Malinau to present certain points of view to policy makers.

\section{LESSONS LEARNED FOR IMPLEMENTING EFFECTIVE PARTICIPATORY MODELING}

\section{Select the appropriate tools}

It is essential to have sound reasons for embarking upon participatory modeling. In the Subtropical Thicket Biome case study, participatory modeling was probably not the appropriate approach. It may have been more effective to develop a GIS-based decision support system combined with expert judgment to choose the best mix of conservation options. In the Namaqualand case, participatory modeling was also probably inappropriate - simple spreadsheets could have been used to compare scenarios, and could have been used as the basis for discussion in stakeholder and policy forums. Vennix (1996: 106) states "...system dynamics is appropriate in situations where (a) the problem is dynamically complex because of underlying feedback processes, and (b) one looks for robust long term solutions." In the Subtropical Thicket Biome and Namaqualand cases, stakeholders were beyond the phase where the problem had to be well defined and the underlying causes explored. Rather, they were in the planning phase of detailed information gathering to make a better comparison between different options. For an overview of what approach to use in what situation, we refer to Chapter 4 in Vennix (1996).

\section{Invite the right stakeholders}

For the modeling to help in the exchange of different viewpoints, a sufficiently broad range of stakeholders should be involved in the model building process. Participants with good connections to policy makers should be invited to ensure the modeling results in impact.

\section{Modeling is just one of various instruments in the toolkit}

Participants noted a limitation of participatory modeling. They mentioned that it was "narrow" since it selected only one or a few options for deeper exploration. Hisschemöller et al. (2001) state "Since models are only capable of analyzing wellstructured problems, models are necessary but not sufficient tools to identify and define the problem to be evaluated...". Modeling should be seen as one of a broader set of tools that help to implement a landscape approach. 
Another limitation arises from processes that are extremely difficult to simulate. Many proponents of modeling advocate the use of soft system variables ("e.g., degree of social cohesion") (Sterman 1991, Vanclay et al. 2006), but we have found that stakeholders are highly skeptical of including such variables (Sandker et al. 2008).

\section{Value of the process}

Some of the most interesting insights and the more valuable discussions of possible scenarios came before the detailed modeling. Thus, the visioning phase is crucial. One participant commented "The modeling is good for helping the process of identifying possible strategies and policies. However, the future remains subject to uncertainty and therefore scenarios should be seen as an additional source of information but not as a prediction of reality." This view is in accordance with the concept of a throw-away model.

\section{Facilitation}

Good facilitation helps ensure stakeholders engage meaningfully with each other and the model does not become overly complex. In addition, the facilitator has an important role in encouraging participants to challenge conventional wisdom. Facilitation does not stop at the end of a modeling workshop. The most significant impacts have come where the facilitator has remained involved over several years and so has been able to update and adapt the model to address emerging problems. Participatory modeling can form a key input during processes of change, for identifying opportunities and constraints (Cowling et al. 2008).

\section{Dealing with time constraints}

It was often challenging to realize all mentioned objectives of participatory modeling given stakeholders' time constraints. If the modeling goes too slowly, you risk not getting to the bottom of the problem and limiting the outcomes to knowledge exchange. If the modeling goes too quickly, you risk losing comprehension by some stakeholders who consequently might feel little ownership of the model, which often results in little uptake of its outcomes. Ideally, as explained by Beall (2007), the modeling is realized on different places along the "hands on" continuum, from an active use of the modeling software by the participants to more technical model "fixing" by the facilitator, who in the absence of the participants, translates stakeholder views into the model. It is therefore important to have a series of meetings, with the facilitator advancing the model in between them. In case of the TNS, for example, the governance issue came up only in the third meeting.

\section{Keeping the model as simple as possible}

Building participatory models reveals a problem common to modeling generally - that of balancing simplicity against accuracy. Scientists feel a need to develop a highly complex model to capture the immense complexity of social-ecological systems because they are often uncomfortable with uncertainty (Knight et al. 2006). There is a perception that the greater the detail, the greater the value in exploring scenarios. In our case, the highest overall scores were given to models with the lowest number of variables, so complexity does not necessarily lead to a more useful model. One participant gave low scores to the degree of reality in the model and its outputs, commenting "due to the complexity and the frequent lack of data of sufficient quality, the model is merely good to give very rough indications; the big trends are probably right though". This is exactly the aim of the throwaway model - to gain understanding of general system functioning. It is not suitable for precise predictions. It is also unrealistic to expect stakeholders to commit long periods of time to modeling. Some of the more successful participatory modeling exercises, the exercise in Ghana for example, were completed within 3-5 days. A balance needs to be found between those improvements to the model that are essential for the exploration of scenarios and those that yield only marginal improvements in outputs.

\section{CONCLUSION}

Process came out as the most valued aspect of participatory modeling, which suggests that the approach of the throw-away model was valued by the participants. These findings concur with Vennix (1996: 98) who reports "...most insights are gained during rather than after the model building process." Specifically, the modeling process was valued in its ability to stimulate information exchange and strategy discussions.

In most case studies, a wide range of disciplines were involved from the outset, and disciplinary 
issues were not the biggest challenge. Challenges related more to reconciling the diverse views of the stakeholders involved (scientists, staff of local and international NGOs, stakeholders with connections to the policy process) than to the disciplinary mix. The evaluation results demonstrate that engaging stakeholders is not a simple process because different stakeholders sometimes have wideranging perspectives on what is valuable in the participatory process. Scientists typically were more critical of the modeling, while stakeholders with policy connections valued the model's role in informing decision makers. King and Kraemer (1993) discuss the division between scientists and policy makers and the low uptake by policy makers of 'scientific' modeling results (referring to predictive models of physical processes of the environment). Participatory modeling is apparently better able to reach policy audiences, though it may lack some credibility with scientists.

It takes careful judgment to determine when participatory modeling can be usefully applied. Strong facilitation of the modeling process is essential to keep the focus on "models as stories" rather than models becoming the end in themselves. Participatory modeling is not a panacea for solving the difficult problems of reconciling conservation and development at landscape scales. However, with skilled facilitation, models can be powerful tools to help stakeholders better understand the dynamics of landscapes and improve their decision making and investments in natural resource management. Therefore, they certainly help in taking a landscape approach.

Responses to this article can be read online at: http://www.ecologyandsociety.org/vol15/iss2/art13/ responses/

\section{Acknowledgments:}

We acknowledge the European Union, the Swedish International Development Cooperation Agency, the International Fund for Agricultural Development, the Global Environment Facility, the World Wide Fund for Nature International, and the International Union for Conservation of Nature for funding various components of this review and the case studies.

\section{LITERATURE CITED}

Akkermans, H. A., and J. A. M. Vennix. 1997. Clients' opinions on group model-building: an exploratory study. System Dynamics Review 13:331 .

Babbie, E. 1989. The practice of social research. Fifth edition. Wadsworth Publishing Company, Belmont, California, USA.

Beall, A. M. 2007. Participatory environmental modeling and system dynamics: integrating natural resource science and social concerns. Dissertation. Washington State University, Washington, USA.

Bennett, E. M., S. R. Carpenter, G. D. Peterson, G. S. Cumming, M. Zurek, and P. Pingali. 2003. Why global scenarios need ecology. Frontiers in Ecology and Environment 1:322-329.

Bousquet, F., J.-C. Castella, G. Trébuil, C. Barnaud, S. Boissau, and S. P. Kam. 2007. Using multi-agent systems in a companion modeling approach for agroecosystem management in Southeast Asia. Outlook on Agriculture 36(1):57-62.

Bousquet, F., and C. Le Page. 2004. Multi-agent simulations and ecosystem management: a review. Ecological Modelling 176:313-332.

Castella, J.-C., S. P. Kam, D. D. Quang, P. H. Verburg, and C. T. Hoanh. 2007. Combing topdown and bottom-up modelling approaches of land use/cover change to support public policies: application to sustainable management of natural resources in Northern Vietnam. Land Use Policy 24 (3):531-545.

Castella, J.-C., T. N. Trung, and S. Boissau. 2005. Participatory simulation of land-use changes in the northern mountains of Vietnam: the combined use of an agent-based model, a role-playing game, and a Geographic Information System. Ecology and Society 10:27. [online] URL: http://www.ecologya ndsociety.org/vol10/iss1/art27/.

Costanza, R., and M. Ruth. 1998. Using dynamic modeling to scope environmental problems and build consensus. Environmental Management 22:183-195. 
Cowling R. M., B. Egoh, A. T. Knight, P. O'Farrel, B. Reyers, M. Rouget, D. Roux, A. Welz, and A. Wilhelm-Rechman. 2008. An operational model for mainstreaming ecosystem services for implementation. Proceedings of the National Academy of Science 105(28):9483-9488.

García-Barrios, L. E., E. N. Speelman, and M. S. Pimm. 2008. An educational simulation tool for negotiating sustainable natural resource management strategies among stakeholders with conflicting interests. Ecological Modelling 210:115-126.

Garnett, S. T., J. Sayer, and J. du Toit. 2007. Improving the effectiveness of interventions to balance conservation and development: a conceptual framework. Ecology and Society 12(1): 2. [online] URL: http://www.ecologyandsociety.org/ vol12/iss 1/art2/.

Hisschemöller, M., R. S. J. Tol, and P. Vellinga. 2001. The relevance of participatory approaches in integrated environmental assessment. Integrated Assessment 2:57-72.

Hoffman, M. T., and R. F. Rohde. 2007. From pastoralism to tourism: the historical impact of changing land use practices in Namaqualand. Journal of Arid Environments 70(4):641-658.

James, I., M. T. Hoffman, R. M. Cowling, R. Roberts, B. M. Campbell, R. Boumans, and N. Allsopp. 2005. Valuing Namaqualand's natural resources: the costs and benefits of communal, commercial and conservation land use practices in Namaqualand incorporating ecological, economic and social values. Leslie Hill Institute for Plant Conservation, University of Cape Town and Terrestrial Ecology Research Unit, Nelson Mandela Metropolitan University.

Kassa, H., B. Campbell, M. Sandewall, M. Kebede, Y. Tesfaye, G. Dessie, A. Seifu, M. Tadesse, E. Garedew, and K. Sandewall. 2009. Building future scenarios and uncovering persisting challenges of participatory forest management in Chilimo Forest, Central Ethiopia. Journal of Environmental Management 90:1004-1013.

King, J. L., and K. L. Kraemer. 1993. Models, facts, and the policy process: the political ecology of estimated truth. Pages 353-360 in M. F. Goodchild, B. O. Parks, and L. T. Steyaert, editors.
Environmental Modeling with GIS. Oxford Univeristy Press, New York, USA.

Knight, A. T., A. Driver, R. M. Cowling, K. Maze, A. F. Boshoff, M. A. Botha, J. G. Castley, P. G. Desmet, P. S. Goodman, A. T. Lombard, K. MacKinnon, S. M. Pierce, M. Rouget, R. SimsCastley, W. I. Stewart, and A. von Hase. 2006. Designing systematic conservation assessments that promote effective implementation: best practice from South Africa. Conservation Biology 20(3):739-750.

Lynam, T., F. Bousquet, C. Le Page, P. d'Aquino, O. Barreteau, F. Chinembiri, and $B$. Mombeshora. 2002. Adapting science to adaptive managers: spidergrams, belief models, and multiagent systems modeling. Conservation Ecology 5:24.

Lynam, T., W. de Jong, D. Sheil, T. Kusumanto, and K. Evans. 2007. A review of tools for incorporating community knowledge, preferences, and values into decision making in natural resources management. Ecology and Society 12:5. [online] URL: http://www.ecologyandsociety.org/vol12/iss1/ art5/.

McShane, T. O., and M. P. Wells. 2003. Getting biodiversity projects to work: towards more effective conservation and development. Columbia University Press, New York, New York, USA.

Mittermeier, R. A., M. Hoffmann, J. D. Pilgrim, T. B. Brooks, C. G. Mittermeier, J. L. Lamoreux, and G. da Fonseca, editors. 2004. Hotspots revisited: Earth's biologically richest and most endangered ecoregions. Cemex, Mexico City, Mexico.

Otto, P., and J. Struben. 2004. Gloucester fishery: insights from a group modeling intervention. System Dynamics Review 20:287-312.

Pala, Ö., and J. A. M. Vennix. 2005. Effect of system dynamics on systems thinking inventory task performance. System Dynamics Review 21:147-172.

Peterson, G. D., G. Cumming, and S. R. Carpenter. 2003. Scenario planning: a tool for conservation in an uncertain world. Conservation Biology 17:358-366. 
Rouwette, E. A. J. A., J. A. M. Vennix, and T. van Mullekom. 2002. Group model building effectiveness: a review of assessment studies. System Dynamics Review 18:5-45.

Sandker, M., B. M. Campbell, Z. Nzooh, T. Sunderland, V. Amougou, L. Defo, and J. Sayer. 2009. Exploring the effectiveness of integrated conservation and development interventions in a Central African forest landscape. Biodiversity and Conservation 18:2875-2892.

Sandker, M., B. Campbell, and A. Suwarno. 2008. What are participatory scoping models? Ecology and Society 13(1):r2. [online] URL: http:// www.ecologyandsociety.org/vol13/iss1/resp2/.

Sandker, M., S. K. Nyame, J. Förster, N. Collier, G. Shepherd, D. Yeboah, D. Ezzine-de Blas, M. Machwitz, S. Vaatainen, E. Garedew, G. Etoga, C. Ehringhaus, J. Anati, O. D. K. Quarm, and B. M. Campbell. 2010. REDD payments as incentive for reducing forest loss: a case from Ghana. Conservation Letters 3:114-121.

Sandker, M., A. Suwarno, and B. M. Campbell. 2007. Will forests remain in the face of oil palm expansion? Simulating change in Malinau, Indonesia. Ecology and Society 12(2):37. [online] URL: http://www.ecologyandsociety.org/vol12/iss2/ $\underline{\operatorname{art} 37 /}$.

Sayer, J., and B. Campbell. 2004. The science of sustainable development: local livelihoods and the global environment. Cambridge University Press, Cambridge, UK.

Sayer, J. A., and S. Maginnis, editors. 2005. Forests in landscapes. Ecosystem approaches to sustainability. Earthscan, London, UK.

Snabe, B., and A. Grossler. 2006. System dynamics modelling for strategy implementation case study and issues. Systems Research and Behavioral Science 23(4):467-481.

Steenkamp Y., A. E. van Wyk, J. E. Victor, D. B. Hoare, A. P. Dold, R. M. Cowling, and G. F. Smith. 2004. Maputaland-Pondoland-Albany Hotspot. Pages 218-229 in R. A. Mittermeier, M. Hoffmann, J. D. Pilgrim, T. B. Brooks, C. G. Mittermeier, J. L. Lamoreux, and G. da Fonseca, editors. 2004.
Hotspots revisited: Earth's biologically richest and most endangered ecoregions. Cemex, Mexico City.

Sterman, J. D. 1991. A skeptic's guide to computer models. Pages 209-229 in G. O. Barney, W. Kreutzer, and M. J. Garrett, editors. Managing a nation: the microcomputer software catalog. Westview Press, Boulder, Colorado, USA.

Sterman, J. D., editor. 2000. Business dynamics systems thinking and modeling for a complex world. Irwin/McGraw-Hill, Boston, Massachusetts, USA.

Vanclay, J. K., R. Prabhu, and F. Sinclair. 2006. Realizing community futures: a practical guide to harnessing natural resources. Earthscan, London, UK.

Van den Belt, M. 2004. Mediated modelling: a systems dynamic approach to environmental consensus building. Island Press, Washington, D. C., USA.

Van den Belt, M., L. Deutsch, and A. Jansson. 1998. A consensus-based simulation model for management in the Patagonia coastal zone. Ecological Modelling 110:79-103.

Vennix, J. A. M. 1996. Group model building: facilitating team learning using system dynamics. John Wiley \& Sons Ltd, Chichester, UK.

Vennix, J. A. M., H. A. Akkermans, and E. A. J. A. Rouwette. 1996. Group model-building to facilitate organizational change: an exploratory study. System Dynamics Review 12:39-58. 
APPENDIX 1. The questions for each of the four characteristics describing participatory modeling with mean scores by case study.

Value of participatory modeling in Malinau terms of:

Wasa Amenfi
TNS

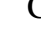

4

1. 1. understanding/

Model conceptualization of system building

process
2. getting a common understanding of problems at hand

3. building consensus on way forward

4. creating awareness of different viewpoints

5. enhancing out-of-discipline thinking

6. focusing on most relevant problems

Mean score "process"

$2 . \quad 1$ the user-friendliness of the Model Stella software structure

2. the ease to run or alter the model

3. the sense of ownership of model

4. the degree to which the model approaches reality

5. the completeness of the model
4

4

4

4

4

4.1

4

3

4

3

4
4

4

4

$$
4
$$

4

5

4

5

4.2

Thicke

Biome
Mean scores land

scores

4.3 


\begin{tabular}{|c|c|c|c|c|c|c|c|c|}
\hline & 6. capturing complexity & 4 & 3 & 4 & 4 & 3 & 3 & 3.6 \\
\hline & Mean score "structure" & 3.4 & 3.6 & 3.7 & 3.5 & 2.6 & 3.2 & 3.5 \\
\hline \multirow[t]{2}{*}{$\begin{array}{l}3 . \\
\text { Model } \\
\text { outputs }\end{array}$} & $\begin{array}{l}\text { 1. the degree to which model } \\
\text { outputs are believable }\end{array}$ & 3 & 3 & 4 & 4 & 3 & 4 & 3.3 \\
\hline & $\begin{array}{l}\text { 2. identifying best options } \\
\text { for impact (optimization) }\end{array}$ & 5 & 3 & 4 & 4 & 1 & 4 & 3.5 \\
\hline & 3. formulation of strategy & 4 & 4 & 3 & 4 & 2 & 3 & 3.3 \\
\hline & 4. supporting decision making & 4 & 3 & 3 & 4 & 1 & 3 & 3.0 \\
\hline & 5. supporting policy formulation & 4 & 4 & 4 & 5 & 2 & 3 & 4.0 \\
\hline & 6. communicating strategy & 4 & 4 & 3 & 4 & 1 & 3 & 3.4 \\
\hline & Mean score "outputs" & 3.9 & 3.6 & 3.7 & 4.1 & 1.5 & 3.0 & 3.5 \\
\hline \multirow[t]{6}{*}{$\begin{array}{l}4 . \\
\text { Impact } \\
\text { after } \\
\text { model- } \\
\text { ing }\end{array}$} & $\begin{array}{l}\text { 1. improving performance of } \\
\text { interventions }\end{array}$ & 4 & 3 & 3 & 3 & 2 & 2 & 2.9 \\
\hline & $\begin{array}{l}\text { 2. actual changing the focus of } \\
\text { interventions }\end{array}$ & 4 & 4 & 3 & 4 & 1 & 2 & 3.1 \\
\hline & 3. actual changing the strategy & 4 & 3 & 2 & 4 & 1 & 3 & 2.9 \\
\hline & 4. actual use in policy formulation & 4 & 4 & 1 & 4 & 2 & 2 & 2.6 \\
\hline & $\begin{array}{l}\text { 5. actual use to communicate } \\
\text { strategy }\end{array}$ & 4 & 3 & 3 & 4 & 1 & 2 & 3.2 \\
\hline & Mean score "impact" & 4.1 & 3.3 & 2.9 & 3.8 & 1.3 & 2.1 & 3.1 \\
\hline
\end{tabular}

